\title{
HLA class II DR, DQ, and DP restriction fragment length polymorphisms in rheumatoid arthritis
}

\author{
W M HOWELL, ${ }^{1}$ P R EVANS , ${ }^{1}$ P J WILSON ${ }^{2}$ M I D CAWLEY ${ }^{3}$ AND J L SMITH ${ }^{1}$ \\ From the ${ }^{1}$ Wessex Regional Immunology Service, Southampton General Hospital; the ${ }^{2}$ Tissue Typing \\ Laboratory, Wessex Regional Transfusion Centre, Southampton; and the ${ }^{3}$ Rheumatology Unit, Southampton \\ General Hospital, Southampton
}

SUMMARY HLA class II restriction fragment length polymorphisms (RFLPs) were studied in 43 individuals with established seropositive rheumatoid arthritis (RA) and in a group of healthy controls. All patients and controls were tissue typed for HLA-A, B, and DR antigens. Rapid, initial screening for RA associated RFLPs was conducted by pooling DNA samples from 11 HLA-DR4 positive patients with RA and comparing the RFLP patterns with those seen in a pool of DNA samples drawn from 11 HLA-DR4 positive healthy controls. Candidate RA associated RFLPs were examined in our full panel of patients with RA and controls. In most cases the RFLPs detected showed no significant association with RA. An exception was a $13.0 \mathrm{~kb}$ DraI DQ $\beta$ associated RFLP, which, when HLA-DR4 positive patients with RA and controls were considered alone, showed a weak positive association with susceptibility to RA. This RFLP was not associated with known DR, DQ, or Dw specificities. These results show a distinct paucity of class II RA associated RFLPs but may indicate a role for DQ $\beta$ genetic variation in the aetiology of RA.

Key words: rheumatoid arthritis susceptibility, HLA-DR4.

There is a well documented association between the HLA class II DR4 antigen and susceptibility to rheumatoid arthritis (RA) in most ethnic groups studied. ${ }^{1}$ This is supported by evidence of haplotype sharing in affected sib pairs in multicase families with RA. ${ }^{2}{ }^{3}$ This DR4 association with RA is weak (relative risk=4), however, and, furthermore, the DR4 antigenic specificity is heterogeneous at the cellular, serological, biochemical, and molecular genetic levels. ${ }^{45}$ Also, up to one third of patients with RA do not carry the DR4 antigen. Thus it is unlikely that DR4 represents the most precise class II genetic marker for RA susceptibility.

The HLA class II region is divided into three main subregions: DR, DQ, and DP. These DR, DQ, and DP antigens are expressed as highly polymorphic transmembrane $\alpha / \beta$ heterodimers, with most polymorphism residing in the $\beta$ chains. The DR antigens are known to be in strong linkage disequilibrium

Accepted for publication 22 August 1988.

Correspondence to Dr W M Howell, Wessex Regional Immunology Service, Tenovus Research Laboratory, Southampton General Hospital, Tremona Rd, Southampton SO9 4XY, UK. with DQ, but less strongly with DP. ${ }^{6}$ Therefore an apparent association between DR4 and susceptibility to RA may reflect linkage disequilibrium between DR4 and an RA susceptibility gene elsewhere in the class II region. In consequence more precise HLA and RA associations may be detectable at the gene level using gene probing, Southern blotting, and restriction fragment length polymorphism (RFLP) analysis. In this study we examined DR $\beta$, $\mathrm{DQ} \alpha, \mathrm{DQ} \beta, \mathrm{DP} \alpha$, and DP $\beta$ RFLPs and their association with RA.

\section{Patients, materials, and methods}

PATIENTS AND CONTROLS

Forty three patients (26 female, 17 male) from Southampton with established classical or definite and seropositive RA without Felty's syndrome were included in this study. An identical number of healthy controls were selected from among laboratory staff, blood donors, and members of the local bone marrow donor panel.

CELL LINES

Eight HLA-DR4 homozygous typing cell lines of 
known HLA-Dw and DQ types were used to investigate possible RFLP correlations with the Dw4, Dw10, Dw13, Dw14, DKT2, and TA10 (DQw7) specificities associated with DR4.

\section{HLA TISSUE TYPING}

HLA tissue typing was performed by standard two stage National Institutes of Health microlymphocytotoxicity tests, using well defined sera for common Caucasian HLA-A, HLA-B, and HLA-DR1, 2, 3, 4,5 , w6, 7, and w8 antigens.

\section{RESTRICTION ENZYMES}

The full panel of 16 restriction enzymes used consisted of six enzymes cleaving at four base pair recognition sites-AluI, CfoI, HaeIII, MspI, RsaI, and TaqI-and 10 enzymes cleaving at six base pair recognition sites-ApaI, BamHl, BglII, DraI, EcoRV, HindIII, KpnI, PstI, PvuII, and XbaI.

\section{PROB ES}

The following gene probes were used in the RFLP analysis: HLA-DR $\beta$ pRTVl, ${ }^{7}$ HLA-DQ $\alpha$ pDCHl, ${ }^{8}$ HLA-DQ $\beta$ pII- $\beta-I,{ }^{9}$ HLA-DP $\alpha$ pSB $\alpha,{ }^{10}$ and HLA$D P \beta .{ }^{11}$ The respective gene inserts were excised from low gelling temperature agarose gels after appropriate endonuclease restriction (generating $517 \mathrm{bp}$ PstI DR $\beta, 794$ bp PstI DQ $\alpha, 620$ bp AvaI DQ $\beta, 1150$ bp EcoRI DP $\alpha$, and 1000 bp EcoRI/Hind III DP $\beta$ gene fragments) and radiolabelled with $\alpha-\left[{ }^{32} \mathrm{P}\right] \mathrm{dCTP}$ by the random hexanucleotide primer method. ${ }^{12}$
DNA PREPARATION, DIGESTION, SOUTHERN BLOTTING, AND RFLP ANALYSIS

High molecular weight DNA was prepared from? peripheral blood or homozygous typing cell lines according to established procedures. ${ }^{7}$ DNA pool흔. were constructed by mixing equal amounts of DNA from either 11 unrelated DR4 positive patients with RA or 11 unrelated DR4 positive controls, using the method of Arnheim et al. ${ }^{13}$ For each experiment $10 \mu \mathrm{g}$ of DNA was digested with $5 \mathrm{U} / \mu \mathrm{g}$ restriction enzyme under conditions specified by the manufac $\vec{w}$ turers. After restriction, DNA fragments were sepa rated by size via electrophoresis through $0.7 \%$ agarose gels and transferred to nylon (Hybond-N) filters according to the method of Southern. ${ }^{14}$ These filters were hybridised with ${ }^{32} \mathbf{P}$ labelled probesi under standard conditions. ${ }^{7}$ Hybridising bands werer visualised by autoradiography for 3-10 days af $-70^{\circ} \mathrm{C}$ using Fuji-RX film. After autoradiographythe probe was removed from filters by washing with $0.4 \mathrm{M} \mathrm{NaOH}$ at $45^{\circ} \mathrm{C}$ for 30 minutes, followed by $0 \cdot 1 \times \operatorname{SSC}(0.15 \mathrm{M} \mathrm{NaCl}+0.015 \mathrm{M}$ sodium citrate) $\overrightarrow{0}$ $0 \cdot 1 \%$ sodium dodecyl sulphate, $0.2 \mathrm{M}$ trometamopo (TRIS)- $\mathrm{HCl} \mathrm{pH} 7.5$ at $45^{\circ} \mathrm{C}$ for a further 30 minutes Filters were subsequently sequentially rehybridisece with further gene probes. Candidate RFLPs so detected were finally examined in an extended pane of patients with RA and healthy controls on arf individual basis.

\section{Results}

All patients with RA entered into this study wer

Table 1 Candidate rheumatoid arthritis $(R A)$ associated restriction fragment length polymorphisms (RFLPS) detected by the DNA pooling method

\begin{tabular}{|c|c|c|c|}
\hline \multirow[t]{2}{*}{ Enzyme } & \multicolumn{3}{|l|}{ Probe } \\
\hline & $D R \beta$ & $D Q \alpha$ & $D Q \beta$ \\
\hline AluI & - & - & - \\
\hline ApaI & NT & - & NT \\
\hline BamH1 & - & - & $\overline{\mathrm{NT}}$ \\
\hline BglII & - & - & NT \\
\hline Cfol & - & - & - \\
\hline DraI & - & - & $+(13.0 \mathrm{~kb} \uparrow, 6.8 \mathrm{~kb} \uparrow, 2.4 \mathrm{~kb} \uparrow$ \\
\hline EcoRV & NT & - & NT \\
\hline HaelII & NT & - & NT \\
\hline HindIII & NT & - & - \\
\hline KpnI & - & - & NT \\
\hline MspI & NT & $+(6 \cdot 3 \mathrm{~kb} \uparrow)$ & - \\
\hline PstI & - & $+(6.4 \mathrm{~kb} \uparrow)$ & - \\
\hline PvulI & - & - & - . \\
\hline RsaI & - & $+(1.9 \mathrm{~kb} \uparrow, 1.4 \mathrm{~kb} \downarrow)$ & - \\
\hline TaqI & - & - & - \\
\hline XbaI & - & - & - \\
\hline
\end{tabular}




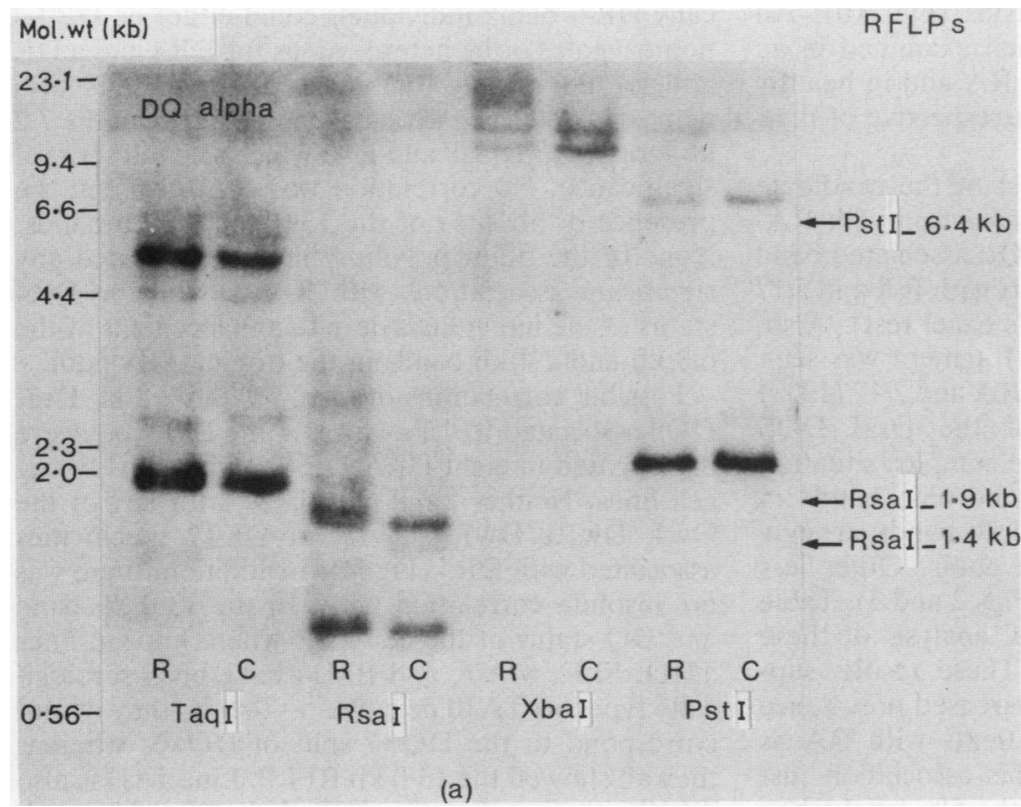

Fig. 1 Restriction fragment length polymorphism (RFLP) analysis of rheumatoid arthritis $(R A)$ and control DNA pools (a) after restriction with TaqI, RsaI, XbaI, and Pstl followed by hybridisation with the $D Q \alpha$ probe and (b) after DraI restriction and $D Q \beta$ hybridisation. $R$ denotes $R A D N A$ pool and C control pool. Numbers on the left denote molecular weight markers in $k b$ while those on the right denote RFLPs in $k b$.

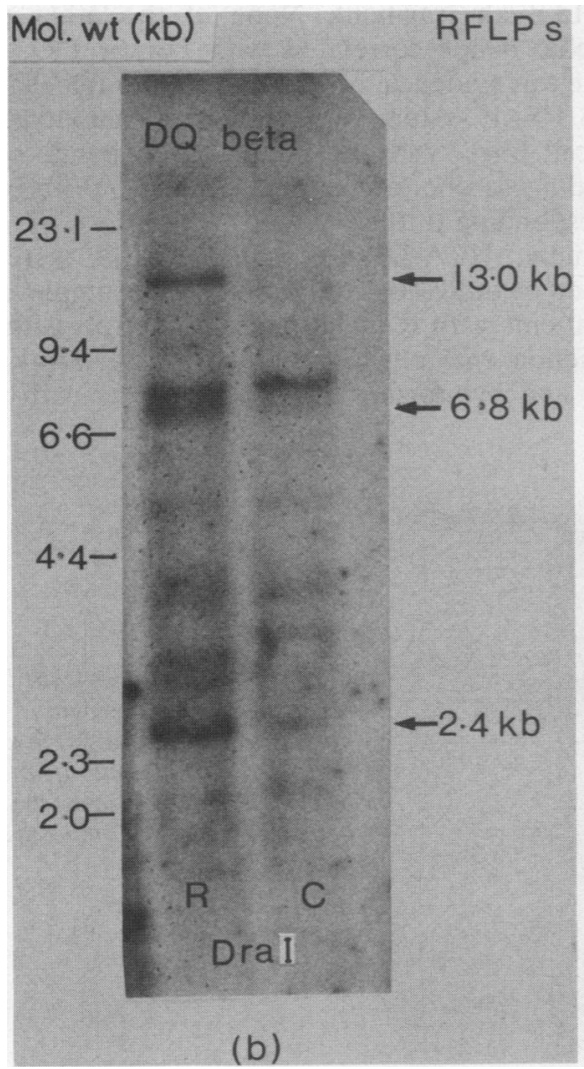

tissue typed for HLA-A, B, and DR antigens. Thirty of the 43 patients were DR4 positive, corresponding to a prevalence of $70 \%$, while a smaller cohort of 11 patients was DR1 positive $(26 \%)$. Four patients were DR1,4 heterozygotes, while the remaining six patients showed a range of DR antigenic specificities. Among the United Kingdom population at large the prevalence of DR4 is $36 \%$ and of $\mathrm{DRl}$ is $16 \%{ }^{15}$ These results indicate primary DR4-RA and secondary DR1-RA associations in our patient population.

Candidate RA associated RFLPs were sought using our full panel of 16 restriction enzymes in conjunction with $\mathrm{DR} \beta, \mathrm{DQ} \alpha$, and $\mathrm{DQ} \beta$ gene probes, using the DNA pooling technique. Several candidate RA associated RFLPs were detected by the criterion of relative band intensity in the RA pool digest compared with the control pool, for a particular restriction enzyme/probe combination. Table 1 gives the full results and Fig. 1 examples of some of these RFLPs (together with nonpolymorphic RA/control pool pairs).

Probing with DR $\beta$ failed to show any candidate RA associated RFLPs. DQ $\alpha$ probing, however, showed possible RA associated RFLPs with MspI (6.3 $\mathrm{kb}$ band enhanced in RA pool-data not shown), PstI (6.4 kb band enhanced in RA poolFig. 1a), and RsaI (1.9 kb band enhanced in RA pool and $1.4 \mathrm{~kb}$ band diminished-Fig. 1a). DQ $\beta$ probing showed that $13 \cdot 0,6 \cdot 8$, and $2 \cdot 4 \mathrm{~kb}$ DraI polymorphisms were enhanced in the RA pool, plus 
evidence of further polymorphisms (Fig. 1b). All these candidate RFLPs were then examined in an extended panel of patients with RA and in healthy controls on an individual basis, irrespective of their DR type.

In this expanded analysis most of the candidate RFLPs showed no significant association with RA. For example, the $1.4 \mathrm{~kb}$ RsaI DQ $\alpha$ associated band was present in $8 / 17(47 \%)$ patients with RA and 5/17 $(29 \%)$ controls $(p=0 \cdot 16$; Fisher's exact test). Also, the $6.4 \mathrm{~kb}$ PstI DQ $\alpha$ associated fragment was seen both in $2 / 17(12 \%)$ patients with RA and $2 / 17(12 \%)$ controls. Individual analysis of the DraI DQ $\beta$ associated RFLPs showed a more complex situation with $7 \cdot 2,3 \cdot 0$, and $2 \cdot 7 \mathrm{~kb}$ polymorphic bands in addition to the $13 \cdot 0,6 \cdot 8$, and $2 \cdot 4 \mathrm{~kb}$ bands strongly detected as polymorphic in the pools. Other less frequent bands were also seen (Figs 2 and 3 ). Table 2 gives full results and statistical analysis of these DraI DQ $\beta$ associated RFLPs. These results supported our initial finding of an increased prevalence of the $13.0 \mathrm{~kb}$ band among patients with RA as detected in the DNA pools. This association just failed to achieve significance at the $5 \%$ level when all patients with RA and controls, irrespective of their DR type, were considered. Among DR4 positive patients with RA and controls alone this $13.0 \mathrm{~kb}-\mathrm{RA}$ association was apparently stronger, reaching significance at the $5 \%$ level. Nevertheless, the $13.0 \mathrm{~kb}$ band was detected among some nonDR4 patients with RA. Also, there was no evidence of enhancement of the $13.0 \mathrm{~kb}$ band in those individuals (both patients and controls) serologically typed as DR4, blank (see Figs 2 and 3), which there might have been if some of these individuals were DR4,4 homozygotes and the $13.0 \mathrm{~kb}$ band was associated with DR4 rather than with RA (theoreti- cally DR4, blank individuals could either be DR4, 눔 homozygotes or be heterozygous for DR4 and a DR: antigen not typed for). The same analysis also? demonstrated a negative association between the $7 \cdot 2$ kb DraI DQ $\beta$ RFLP and RA, which also fell short op significance. No correlation was seen between the presence or absence of the 13.0 and $7.2 \mathrm{~kb}$ bands $\stackrel{\mathbb{}}{\Omega}$ None of the other polymorphic bands showed anyes significant associations with RA or with the DR4 status of the individuals despite enhancement of the $6.8 \mathrm{~kb}$ and $2.4 \mathrm{~kb}$ bands in the original RA pool. $\vec{\omega}$

Possible correlations of the 13.0 and $7.2 \mathrm{~kb}$ Drap $D Q \beta$ associated RFLPs with Dw and DQ types wer苋 investigated in eight HLA-DR4 homozygous typing cell lines. Neither band correlated with any of the Dw4, Dw10, Dw13, Dw14, or DKT2 specificities associated with DR4 (Fig. 4). In addition, there was no absolute correlation between the $13.0 \mathrm{~kb}$ band and DQ status of the cell lines where known: lines. THO, FLE, MAY, and BM14 have been serologi $\rightarrow$ cally typed as TA10 negative ${ }^{16}$ - that is, they do not. correspond to the DQw7 split of DQw3, whereas they all showed the $13.0 \mathrm{~kb}$ RFLP. Line JAH is alsog TA10 negative, but this lacked the $13.0 \mathrm{~kb}$ band: Line JHA is TA10 positive (DQw7) but also lacked the $13.0 \mathrm{~kb}$ fragment. None of the other polys morphic bands correlated with Dw or DQ type There was evidence, however, for a possible dialleliø̋ DQB RFLP system within the DR4 haplotypes of the cell lines, with 13.0 and $2.4 \mathrm{~kb}$ bands corre $\overrightarrow{0}$ sponding to one 'allele' and 7.2 and $3.0 \mathrm{~kb}$ bands corresponding to the other.

Finally, HLA-DP associated RFLPs were ex: amined by individually digesting DNA samples from 20 patients with RA and from 20 controls with five restriction enzymes (TaqI, MspI, RsaI, DraI, and PstI) and hybridising the blotted filters with DPo

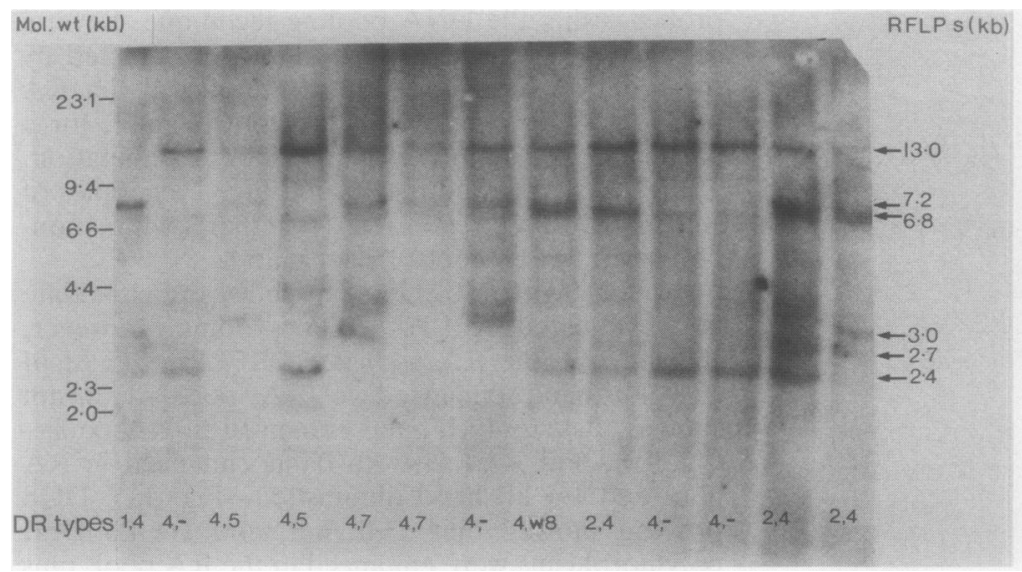

Fig. 2 Dral $D Q \beta$ associated restriction fragment length polymorphisms (RFLPS) in a sample of patients with rheumatoid arthritis. The DR types of the patients are marked on the digest lanes. 


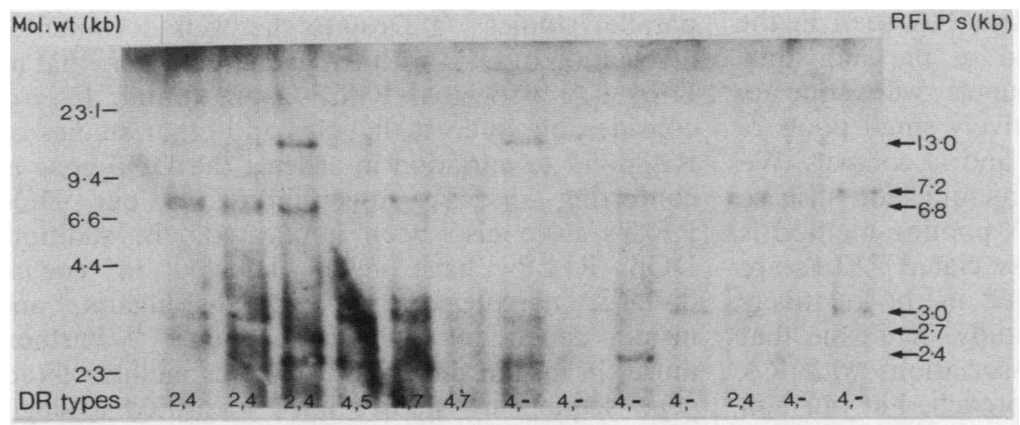

Fig. 3 DraI $D Q \beta$ associated restriction fragment length polymorphisms (RFLPS) in a sample of healthy controls. The DR types of the controls are marked on the digest lanes.

and DP $\beta$ probes. Although some RFLPs were detected-for example with TaqI and DP $\beta$, none proved to be RA associated (data not shown).

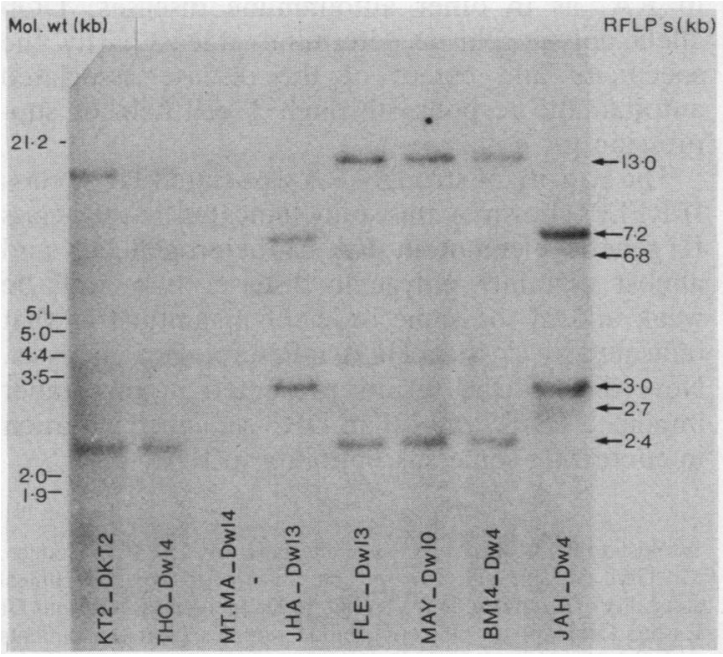

Fig. 4 Dral DQB RFLP analysis of eight HLA-DR4 homozygous typing cell lines. The Dw types of the homozygous typing cell lines used are marked on the digest lanes.

\section{Discussion}

All patients with RA entered into this study showed established classical or definite and seropositive RA. No patients suffered from Felty's syndrome. Confinement of the study to seropositive patients with classical or definite RA eliminated the possibility of inadvertent inclusion of patients suffering from other forms of chronic polyarthritis. HLA tissue typing of these patients with RA plus healthy controls gave results in agreement with national prevalences of DR4 in RA. ${ }^{17}$ A secondary association of DR1 with RA was also seen. This latter association has been observed in some other studies. ${ }^{18} 19$ Thus our Southampton population of patients with RA may be regarded as representative.

Several candidate RA associated RFLPs were detected by the DNA pooling method. Upon further examination in an expanded panel of all patients with RA and controls, irrespective of their DR type, most of these RA-RFLP associations proved nonsignificant. Some associations seen in the DNA pools were no longer apparent-for example, the $1.4 \mathrm{~kb}$ RsaI DQ $\alpha$ RFLP, or the same association was still detected but failed to reach significancefor example, the $2.4 \mathrm{~kb}$ DraI DQ $\beta$ RFLP. These observations require some comment. It is likely that

Table 2 Prevalence of DraI DQB associated restriction fragment length polymorphisms in patients with rheumatoid arthritis (RA) and in controls. Values are Nos (\%)

\begin{tabular}{lllllll}
\hline & \multicolumn{2}{l}{ Band sizes $(k b)$} & & & \\
\cline { 2 - 7 } & $13 \cdot 0$ & $7 \cdot 2$ & $6 \cdot 8$ & $3 \cdot 0$ & $2 \cdot 7$ & $2 \cdot 4$ \\
\hline Patients with RA & $21 / 26(81)$ & $17 / 22(77)$ & $20 / 26(77)$ & $13 / 22(59)$ & $14 / 24(58)$ & $10 / 14(71)$ \\
Controls & $24 / 39(62)$ & $30 / 32(94)$ & $21 / 32(66)$ & $21 / 28(75)$ & $15 / 28(54)$ & $22 / 29(76)$ \\
Probability & 0.06 & 0.07 & $0 \cdot 15$ & 0.12 & $0 \cdot 21$ & 0.27 \\
\hline
\end{tabular}

Among HLA-DR4 positive patients with RA and controls the $13.0 \mathrm{~kb}$ band was present in $14 / 16$ patients (88\%) and $17 / 29$ controls $(59 \%) ; p=0.04$.

Bands were only scored as present or absent when an unambiguous assignment could be made.

Probability values were calculated using $2 \times 2$ contingency tables and Fisher's exact test. 
apparent RFLP associations with RA seen in the DNA pools but not observed in the individual analyses of the expanded panels were due to sampling variation in the relatively small pools of DNA samples from 11 patients and 11 controls. We feel, however, that rapid screening for disease associated RFLPs by the DNA pooling method is still valid as strongly disease associated RFLPs are unlikely to be overlooked, even in the relatively small pools examined in this study. It is true that RFLPs showing only subtle associations with RA may be undetected by this approach, but our aim was to detect HLA class II genetic lesions showing associations with RA stronger than the classic DR4RA associations, if such lesions do exist. Nevertheless, our results did show a significant positive association between a $13.0 \mathrm{~kb}$ DraI $\mathrm{DQ} \beta$ associated RFLP and RA when DR4 positive patients with RA and controls were considered alone. A similar association was seen among all patients with RA and controls, but at a non-significant level. Examination of these results indicates that this RFLP association is with RA, rather than simply a reflection of a primary association with DR4. The same enzyme/ probe combination also showed a non-significant negative association beween a $7 \cdot 2 \mathrm{~kb}$ band and RA. Thus our data demonstrate a trend towards association between DraI DQ $\beta$ associated RFLPs and RA.

Various studies have indicated associations between RA and either or both of the Dw4 or Dw14 cellular specificities associated with DR4, ${ }^{19-21}$ while positive DQß RFLP-TA10 (DQw7)-RA associations have been reported in some other studies. ${ }^{52}$ RFLP analysis of DR4 homozygous typing cell lines showed that the $13.0 \mathrm{~kb}$ DraI DQ $\beta$ associated band did not correlate with any of the Dw4, Dw10, Dw13, Dw14, or DKT2 specificities. Nor was there any absolute correlation with the TA10 serological specificity identifying the DQw7 split of DQw3 (found in DR4 haplotypes). Thus the $13.0 \mathrm{~kb}$ RFLP appears to be a novel genetic marker showing a positive association with RA susceptibility.

No RA associated RFLPs were detected with either of the DP probes. This was not unexpected as DP is not in such strong linkage disequilibrium with DR, and DP antigens show few reported associations with RA or other autoimmune diseases, though certain DP antigens may have some protective role in RA. ${ }^{19}$

Our results demonstrate an absence of DR $\beta$, DQ $\alpha, D P \alpha$, and DP $\beta$ RA associated RFLPs, while a sole DQ $\beta$ RFLP, showing a weak positive association with RA, was detected. Although numbers of patients and controls examined were small, the absence of strongly RA associated RFLPs remains valid and is in broad agreement with the findings of parallel studies. 522 Despite the well documente association of DR4 with RA it is noteworthy that ne: DR $\beta$ RA associated RFLPs were found. It is of considerable interest that this and other studies or RA point to variation in at least the $D Q \beta$ gene a? conferring disease susceptibility, ${ }^{522}$ but DQ⿻ RFLPs have also been implicated. ${ }^{5}$ In addition $\$$ DQ $\beta$ RFLPs have been detected in coeliaes disease, ${ }^{23}$ narcolepsy, ${ }^{24}{ }^{25}$ pemphigus vulgaris, ${ }^{26}$ and insulin dependent diabetes mellitus. ${ }^{27} 28$ Furthermore, in insulin dependent diabetes mellitus direct gene sequencing studies have identified a singl\& amino acid change in the DQ $\beta$ chain of all haplo types associated with this diabetes. ${ }^{29}$ Similai findings have also been obtained for DQ $\beta$ anq pemphigus vulgaris, while DR $\beta$ sequence variation has been detected in RA associated haplotypes

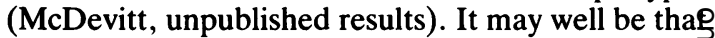
in RA, as in other autoimmune diseases, $D Q \beta$ allelic polymorphisms determine, at least partly, the specificity and extent of the disease associate autoimmune response through $\mathrm{T}$ cell help or $\sup _{\overrightarrow{\mathrm{c}}}$ pression, or both.

The paucity of strongly RA associated HLA class II RFLPs shown by this study indicates that the clas@ II genetic element in RA, a heterogeneous an almost certainly polygenic disease, may well be weak and of the same order of magnitude as thas indicated by classical HLA-DR serological analysis? Nevertheless, the results presented in this pape $\overrightarrow{\vec{E}}$ implicate $D Q \beta$ rather than DR $\beta$ sequence variation in conferring some susceptibility to RA.

We wish to thank Mrs Myfanwy Spellerberg, Ms Elizabeth Hodges Mr Glyn Stacey, and Mrs Alison Stacey for expert technicat assistance. Our gratitude is also due to Dr Melvyn Walters and D. Rashid Luqmani for collecting blood samples from the patients. with RA. Dr Usha Jayaswal was invaluable in the coordination of blood sample collection from the healthy control volunteers who participated in this study. Professor Hiliard Festenstein kindlQ supplied the homozygous typing cell lines used and Mrs Pauline Hutchins provided skilful secretarial support. Dr Howell w\& supported by a Television South Trust medical research fellowship. and financial support from the Wessex Regional Health Authority is also gratefully acknowledged.

\section{References}

1 Tiwari J Terasaki P. HLA and disease associations. New Yor Springer, 1985.

2 Nunez G, Moore S E, Ball G V, Hurd E R, Stastny P. Study HLA antigens in ten multiple-case rheumatoid arthritis families. J Rheumatol 1984; 11: 129-35.

3 Payami H, Thomson G, Kahn M A, et al. Genetics of rheumatoid arthritis. Tissue Antigens 1986; 27: 57-63.

4 Nepom G T, Hansen J A, Nepom B S. The molecular basis for HLA class II associations with rheumatoid arthritis. J Cli Immunol 1987; 7: 1-7.

5 Sansom D M, Bidwell J L, Maddison P J, Campion G, Kloudg $P$ T, Bradley B A. HLA DQ $\alpha$ and DQ $\beta$ restriction fragmen length polymorphisms associated with Felty's syndrome and 
DR4-positive rheumatoid arthritis. Hum Immunol 1987; 19: 269-78.

6 Bodmer W F. The HLA system: structure and function. $J$ Clin Pathol 1987; 40: 948-58.

7 Bidwell J L, Jarrold E A. HLA-DR allogenotyping using exonspecific cDNA probes and application of rapid minigel methods. Mol Immunol 1986; 23: 1111-6.

8 Auffray C, Lillie J W, Arnot D, Grossberger D, Kappes D, Strominger $\mathbf{J}$ L. Isotypic and allotypic variation of human class II histocompatibility antigen $\alpha$-chain genes. Nature 1984; 308: 327-33.

9 Larhammar D, Schenning L, Gustafsson K, et al. Complete amino acid sequence of an HLA-DR antigen-like $\beta$ chain as predicted from the nucleotide sequence: similarities with immunoglobulins and HLA-A, -B and -C antigens. Proc Natl Acad Sci USA 1982; 79: 3687-91.

10 Erlich H, Stetler D, Shang-Dong R, Saiki R. Analysis by molecular cloning of the human class II genes. Fed Proc 1984; 43: 3025-30.

11 Roux-Dosseto M, Auffray C, Lillie J W, et al. Genetic mapping of a human class II antigen $\beta$-chain cDNA clone to the SB region of the HLA complex. Proc Natl Acad Sci USA 1983; 80: 6036-40.

12 Feinberg A P, Vogelstein B. A technique for radiolabelling DNA restriction endonuclease fragments to high specific activity. Anal Biochem 1984; 137: 266-7.

13 Arnheim N, Strange C, Erlich H. Use of pooled DNA samples to detect linkage disequilibrium of polymorphic restriction fragments and human disease: studies of the HLA class II loci. Proc Natl Acad Sci USA 1985; 82: 6970-4.

14 Southern E M. Detection of specific sequences among DNA fragments separated by gel electrophoresis. J Mol Biol 1975; 98: 503-17.

15 Klouda P T, Molnar J, Wasik A, Bodmer J G. HLA-A, B and DR antigens in the British Isles. UK Transplant Service Report. November 1985.

16 Schreuder G M T, Doxiadis I, Parlevliet J, Grosse-Wilde H. HLA-DR, DQ, LB and TA10 specificities of ninth workshop homozygous typing cells. In: Albert E D, Baur M P, Mayr W R, eds. Histocompatibility testing 1984. Berlin: Springer, 1984: 243-8.
17 Jaraquemada D, Ollier W, Awad J. HLA and rheumatoid arthritis: combined analysis of 440 British patients. Ann Rheum Dis 1986; 45: 627-36.

18 Sachs J A, Kirwan J R. Multiple HLA associations and disease susceptibility. Dis Markers 1986; 4: 13-27.

19 Pawelec G, Reeker P, Brackentz D, et al. HLA-DP in rheumatoid arthritis. Tissue Antigens 1988; 31: 83-9.

20 Stastny P. Association of the B-cell alloantigen DRw4 with rheumatoid arthritis. $N$ Engl J Med 1978; 298: 869-71.

21 Nepom G T, Seyfried C E, Holbeck S L, Wilske K R, Nepom B S. Identification of HLA-Dw14 genes in DR4+ rheumatoid arthritis. Lancet 1986; ii: 1002-4.

22 Singal D P, Reid B, Kassam Y B, D'Souza M, Bensen W G, Adachi J D. HLA-DQ beta-chain polymorphism in HLA-DR4 haplotypes associated with rheumatoid arthritis. Lancet 1987; ii: 1118-20.

23 Howell M D, Austin R K, Kelleher D, Nepom G T, Kagnoff $M$ F. An HLA-D region restriction fragment length polymorphism associated with celiac disease. J Exp Med 1986; 164: 333-8.

24 Marcadet A, Gebuhrer L, Betuel $\mathrm{H}$, et al. DNA polymorphism related to HLA-DR2 Dw2 in patients with narcolepsy. Immunogenetics 1985; 22: 679-83.

25 Inoko H, Ando A, Tsuji K, Matsui K, Juji T, Honda Y. HLA$D Q \beta$ chain restriction fragments can differentiate between healthy and narcoleptic individuals with HLA-DR2. Immunogenetics 1986; 23: 126-8.

26 Szafer F, Brautbar C, Tzfoni E, et al. Detection of diseasespecific restriction fragment length polymorphisms in pemphigus vulgaris linked to the DQw1 and DQw3 alleles of the HLAD region. Proc Natl Acad Sci USA 1987; 84: 6542-5.

27 Böhme J, Carlsson B, Wallin J, et al. Only one DQ $\beta$ restriction fragment pattern of each DR specificity is associated with insulin-dependent diabetes. J Immunol 1986; 137: 941-7.

28 Michelson B, Lernmark A. Molecular cloning of a polymorphic DNA endonuclease fragment associates insulin-dependent diabetes mellitus with HLA-DQ. J Clin Invest 1987; 79: 1144-52.

29 Todd J A, Bell J I, McDevitt H O. HLA-DQß gene contributes to susceptibility and resistance to insulin-dependent diabetes mellitus. Nature 1987; 329: 599-604. 